\title{
CORPOCIDADE:
}

\section{ARTE ENQUANTO MICRO-RESISTÊNCIA URBANA}

\author{
Fabiana Dultra Britto $\star$ \\ Paola Berenstein Jacques ${ }^{\star}$
}

\begin{abstract}
RESUMO
Partimos de uma crítica à atual espetacularização das cidades e propomos a necessidade de restituir o caráter político do espaço público por meio da valorização da experiência corporal das cidades, apresentando a idéia de corpografia como uma possibilidade de micro resistência a esse processo segregador e apolítico. O espaço público, se reconhecido, por excelência, como locus do conflito, inclui agentes e mobiliza agenciamentos muito mais diversos e contraditórios do que se desejaria ou se costuma identificar. Enquanto a arte, se reconhecida como locus da experiência, promove percepções espaço-temporais muito mais complexas do que sugerem os efeitos moralizadores e individualistas normalmente atribuídos à contemplação cenográfica.
\end{abstract}

Palavras-chave: cidade; espetacularização; resistência; corpografia.

\section{BODYCITY:}

\section{ART AS URBAN MICRO-RESISTANCE}

\begin{abstract}
We start from the critique about the spetacularization of the cities and purpose the necessity of to return the political character of the public space through the valorization of the bodily experience of the cities, presenting the idea of bodygraphy as a possibility of micro-resistance to these apolitical and segregator process. The public space, if recognized by excellence as the conflict locus, includes agents and mobilizes agenciaments much more diverse and contradictory than

^Doutora em Comunicação e Semiótica (Pontifícia Universidade Católica de São Paulo). Crítica de dança, professora e coordenadora do Programa de Pós-Graduação em Dança da Universidade Federal da Bahia. Entre outros projetos, criou e coordenou o mapeamento da dança contemporânea no Brasil realizado pelo Rumos Dança-2000 do Itaú Cultural e organizou o livro resultante: Cartografia da Dança. Publicou recentemente o livro Temporalidade em Dança (Belo Horizonte, FID, 2008). Endereço: Universidade Federal da Bahia. Av Adhemar de Barros s/n - Ondina. CEP: 40170-110 - Salvador, BA - Brasil.

E-mail: fabritto@ufba.br

$\star \star$ Arquiteta-urbanista, professora da Faculdade de Arquitetura da Universidade Federal da Bahia e vicecoordenadora do PPG-AU/FAUFBA. É autora dos livros: Les favelas de Rio (Paris, l'Harmattan, 2001a); Estética da Ginga (Rio de Janeiro, Casa da Palavra, 2001b); Esthétique des favelas (Paris, l'Harmattan, 2003a); co-autora de Maré, vida na favela (Rio de Janeiro, Casa da Palavra, 2002) ; organizadora de Apologia da Deriva (Rio de Janeiro, Casa da Palavra, 2003b), Corps et Décors urbains (Paris, l'Harmattan, 2006), e Corpos e cenários urbanos (Salvador, Edufba, 2006).

E-mail:paolabj@ufba.br
\end{abstract}


people would like and are used to identify. While the art, if is recognized as the experience locus, promotes space-temporal perceptions much more complex than the moralized and individualists effects that are normally attributed to the scenography contemplation

Keywords: city; spetacularization; resistance; bodygraphy.

\section{Canteiro de obras: o espaço público}

Uma das principais reflexões críticas acerca do cotidiano da vida urbana contemporânea, tematizada em diferentes campos, refere-se ao processo denominado "espetacularização urbana", em alusão às nefastas consequências do processo de privatização dos espaços públicos pela especulação imobiliária e a consequente gentrificação (enobrecimento de áreas com expulsão da população mais pobre) das cidades contemporâneas. Em tais processos, o ambiente urbano tende a se caracterizar como uma cenografia e a experiência urbana cotidiana, por sua vez, então, acaba resumida à utilização e circulação disciplinadas por princípios segregatórios, conservadores e despolitizadores que conferem um sentido mercadológico, turístico e consumista ao seu modo de operação. A crítica hoje ao processo de espetacularização urbana já se tornou recorrente no meio acadêmico, ao menos no campo da arquitetura e do urbanismo, e este processo está cada vez mais explícito. Escutamos muito falar em cidade-museu, cidade genérica, cidade-parque-temático, cidade-shopping, em resumo: cidade-espetáculo, no sentido proposto por Guy Debord (1997).

De tão consolidado esse processo, muitos de seus "efeitos" acabam por tornar-se a própria "lógica" organizativa da dinâmica urbana, atuando de modo estrutural e não mais apenas circunstancial, na medida em que se desvinculam de sua justificativa contextual para generalizarem-se como um "padrão cultural" de pensamento, comportamento e ação.

Tome-se, por exemplo, um processo corretalo conhecido como "turistificação" das cidades que, fortemente ancorado na lógica de consumo típica dos contextos espetacularizados, generalizou-se como um padrão interativo entre pessoas e lugares, que opera, inclusive, em circunstâncias sem qualquer apelo propriamente turístico.

Uma lógica interativa (consumista ou "turistizada") que faz parte do crescente processo de espetacularização da cidade, da cultura e do próprio corpo e que, de tão consolidada, já se manifesta amplamente impregnada na formulação dos discursos e comportamentos que permeiam e, até mesmo, fundamentam desde os planejamentos e ações da administração pública das cidades até as próprias relações mais íntimas de seus habitantes.

O aspecto crucial dessa configuração contemporânea das cidades, que interessa salientar, é o do empobrecimento da experiência urbana dos seus habitantes, cujo espaço de participação civil, de produção criativa e vivência 
afetiva não apenas está cada vez mais restrito quanto às suas oportunidades de ocorrência, mas, inclusive, qualitativamente comprometido quanto às suas possibilidades de complexificação.

Embora esse problema já venha sendo tematizado pelos discursos acadêmicos e da administração pública das cidades, ainda carece de enfrentamento apropriado ao necessário redimensionamento das responsabilidades e implicações, de modo, também, a combater uma certa tendência conciliatória das abordagens que, ao pregar a tese da coexistência pacífica entre diferentes "identidades" acaba por destiná-los cada qual ao "seu espaço próprio" de convivência com iguais, escondendo os inevitáveis conflitos de interesse e instaurando equilíbrios duvidosos.

O espaço público, se reconhecido, por excelência, como locus do conflito, inclui agentes e mobiliza agenciamentos muito mais diversos e contraditórios do que se desejaria ou se costuma identificar. Enquanto a arte, se reconhecida como locus da experiência, promove percepções espaço-temporais muito mais complexas do que sugerem os efeitos moralizadores e individualistas normalmente atribuídos à contemplação cenográfica.

Sob esta perspectiva, qualquer abordagem acerca do ambiente urbano que desconsidere sua dimensão pública nos parece pura especulação como também o será qualquer atuação artística que desconsidere sua dimensão contextual (circunstancial). É exatamente a partir desta constatação que os campos da arquitetura (com os estudos da cidade) e da dança (com os estudos do corpo) demonstram uma possibilidade de interseção criativa e propositiva.

O espaço público e a experiência artística constituem, assim, aspectos da vida humana cuja dinâmica tanto promove quanto resulta dos modos de articulação entre corpo e seus ambientes de existência. Ambiente entendido não propriamente como um lugar, mas como um conjunto de condições interativas para o corpo $^{2}$, permite pensar a própria universidade como um ambiente apropriado para a formulação e experimentação de hipóteses e procedimentos capazes de conferir um novo enquadramento ao problema das relações atuais entre corpo e cidade, a partir da desejável articulação entre teoria e arte.

Sabe-se que a proposta de articular diferentes campos do conhecimento para engendrar reflexões críticas acerca de casos e situações de uma dada realidade é um exercício tão necessário quanto delicado: não raras vezes resulta em impropriedades desrespeitosas tanto aos campos invocados quanto à própria situação analisada.

O exercício de articulação entre arte e urbanismo, passa, pois, necessariamente, pela "desterritorialização" de alguns dos conceitos mais caros às suas respectivas especificidades como o são tempo e espaço, corpo e ambiente. Desse modo, poderão se esboçar novos modos relacionais sugestivos de novos nexos de sentido, tanto aos conceitos quanto às próprias áreas de conhecimento em questão. 
Nesta perspectiva, é possível pensar o debate entre arte e urbanismo não como um encontro de áreas mas como um processo de construção de uma "zona de transitividade", baseada na co-operação entre as condições relacionais de cada área, em busca de conexões que mobilizem experiências re-organizativas de seus respectivos regimes de funcionamento e estados de equilíbrio, de modo que favoreçam a produção de novos sentidos ou, como sugere o filósofo Paul Thagard (2000), a instauração de "coerências". 3

\section{Agenciamento: A Corpografia urbana}

Esse processo de estetização acrítico e segregador,que faz parte do que se conhece por espetacularização urbana - cidade-espetáculo, cidade-cenário - está diretamente relacionado a uma diminuição tanto da participação cidadã quanto da própria experiência corporal das cidades enquanto prática cotidiana, estética ou artística no mundo contemporâneo. Partimos da premissa de que o estudo das relações entre corpo - corpo ordinário, vivido, cotidiano - e cidade, poderia nos mostrar alguns caminhos alternativos, desvios, linhas de fuga, micro-políticas ou ações moleculares de resistência ao processo molar de espetacularização da cidade, da arte e do próprio corpo - na contemporaneidade. A redução da ação urbana, ou seja, o empobrecimento da experiência urbana pelo espetáculo leva a um empobrecimento da corporalidade, os espaços urbanos tornam-se simples cenários, sem corpo, espaços desencarnados, o que incita à reflexão urgente sobre as atuais relações entre urbanismo e corpo, entre o corpo urbano e o corpo do cidadão. Da relação entre o corpo do cidadão e um outro corpo urbano poderão surgir outras formas de apreensão urbano-corporal e, consequentemente, outras formas de reflexão, de relação e de intervenção nas artes e nas cidades contemporâneas.

Quais seriam, então, algumas alternativas ou desvios possíveis ao espetáculo urbano? Todas as pistas nos levam à questão da experiência ou prática dos espaços urbanos. Essas alternativas passariam necessariamente pela própria experiência corporal da cidade. A redução da ação urbana, ou seja, o empobrecimento da experiência urbana pelo espetáculo leva a uma perda da corporeidade, os espaços urbanos se tornam simples cenários, sem corpo, espaços desencarnados. Os novos espaços públicos contemporâneos, cada vez mais privatizados ou não apropriados, nos levam a repensar as relações entre urbanismo e corpo, entre o corpo urbano e o corpo do cidadão. A cidade não só deixa de ser cenário mas, mais do que isso, ganha corpo a partir do momento em que ela é apropriada, vivenciada, praticada, ela se torna "outro" corpo.

Acreditamos que seja dessa relação entre o corpo do cidadão e esse "outro corpo urbano" poderá surgir uma outra forma de apreensão urbana e, consequentemente, de reflexão e de intervenção na cidade contemporânea. Partimos da premissa de que o estudo das relações entre corpo - corpo ordinário, vivido, cotidiano, ou seja, o corpo enquanto possibilidade de micro resistência à espetacularização, o oposto do corpo mercadoria, imagem ou simulacro, produto da própria espetacularização contemporânea e cidade, pode nos mostrar alguns caminhos alternativos, desvios, a este processo sofrido pelas cidades contemporâneas. 
As relações, entre o corpo humano e o espaço urbano, ainda tem sido bastante negligenciada nos estudos urbanos e, principalmente, nos estudos culturais a respeito das cidades. Consideramos que os estudos do corpo influenciaram os estudos urbanos e que corpo e cidade se configuram mutuamente, ou seja, que além de os corpos ficarem inscritos e contribuírem para a formulação do traçado de cidades, as memórias das cidades também ficam inscritas e contribuem para a configuração de nossos corpos.

A cidade é percebida pelo corpo como conjunto de condições interativas e o corpo expressa a síntese dessa interação descrevendo, em sua corporalidade, o que passamos a chamar de "corpografia" urbana. "A corpografia" seria uma espécie de cartografia corporal em que não se distinguem o objeto cartografado e sua representação. Uma ideia baseada na hipótese de que a experiência urbana fica inscrita, em diversas escalas de temporalidade, no próprio corpo daquele que a experimenta, e dessa forma também o define, mesmo que involuntariamente.

\section{Conclusões prospectivas: Arte no EspaÇo Público Urbano}

Os atuais projetos urbanos contemporâneos, ditos de revitalização urbana, estão sendo realizados no mundo inteiro de acordo com uma mesma estratégia : genérica, homogeneizadora e consensual. Estes projetos espetaculares transformam os espaços públicos em cenários, espaços desencarnados, "sem corpo », «pura imagem ». As « cidades » cenográficas contemporâneas estão cada dia mais padronizadas e uniformizadas. Espaços destituídos de seus conflitos inerentes, dos desacordos e dos desentendimentos, ou seja, são espaços apolíticos. Se pensamos, como Jacques Rancière (2005), no desentendimento como categoria fundamental do político, nos conflitos e dissensos que caracterizam a vita activa, a vida pública, estes espaços públicos transformados em imagens espetaculares são a própria negação do político, ou seja, a negação do próprio caráter político desses espaços que está, ou deveria estar, na base de qualquer formulação de esfera pública.

Chantal Mouffe (2007a) ainda é mais radical ao defender a ideia de um modelo agonista, no qual o espaço público é, ao contrário dessas imagens de espaços públicos dos spots publicitários, um eterno campo de batalha no qual enfrentam diferentes projetos, sem possibilidade alguma de conciliação final. $\mathrm{Na}$ perspectiva de Mouffe (2007a) não há possibilidade de emergência de qualquer tipo de consenso no espaço público. Dentro da proposta agonista, os espaços públicos são sempre plurais e a confrontação agonista se produz em uma multiplicidade de superfícies discursivas.

Enquanto a construção de consensos busca reduzir os conflitos e é uma forma ativa de despolitização, o desentendimento, ou a construção de dissensos, seria uma forma de resistência. Rancière (1996), mostra que é precisamente essa configuração consensual que solicita, de diferentes maneiras, a intervenção da arte. É evidente que não se trata aqui da escultura tradicional na praça pública (presente nos cartões postais das cidades) ou ,ainda, da arte pública espetacular, usada para ornar ou embelezar ou ainda tentar "criar novos laços" em espaços públicos problemáticos, ou seja, uma "arte esparadrapo", como diz Henri-Pierre 
Jeudy (1999), que está à serviço do espetáculo e que promove essas imagens de espaços pacificados. Ao contrário, trata-se da arte que poderia ser vista como uma forma de ação dissensual, de construção de espaços dissensuais ou conflituosos, uma possibilidade de explicitação desses conflitos, ou, ainda, como uma potência questionadora de consensos estabelecidos e, sobretudo, explicitadora de tensões do/no espaço público diante dessa atual despolitização consensual.

Pode ser de fato interessante pensar a arte como essa fonte explicitadora ou mantenedora ou até mesmo criadora de tensões no/do espaço público. Chantal Mouffe (2007b, p. 5) faz uma proposta semelhante, no que ela chama de Arte Crítica:

De acordo com a abordagem agonística, arte crítica é a arte que fomenta dissensos, que torna visível o que o consenso dominante tenta obscurecer e esquecer. Esta é constituída por uma série de práticas artísticas que buscar dar voz àqueles que foram silenciados pela estrutura da hegemonia existente.

Essa idéia de dar voz aos silenciados precisa ser relativizada para se evitar o perigo do que Jeudy (1999) chama dos "usos sociais da arte" , muito em voga hoje e que também leva a criação de consensos, sobretudo identitários, o interessante na ideia de Mouffe é o fomento de dissensos, no caráter político do que ela vai chamar de ativismo artístico que, segundo ela, deve ser visto como "intervenções contra-hegemônicas" com o objetivo de ocupar o espaço público para perturbar essa imagem tranquilizadora que o espetáculo do consenso tenta forjar.

Um bom exemplo, dessas práticas artísticas, que podem ser vistas como "intervenções contra-hegemônicas", foi o que aconteceu durante o encontro Corpocidade: debates em estética urbana 1 (2008) e, a partir das diversas intervenções urbanas realizadas por artistas nessa ocasião nos espaços públicos de Salvador.

A partir do amadurecimento da ideia de corpografia como micro-resistência ao empobrecimento da experiência urbana pelo processo citado de espetacularização das cidades, percebemos a necessidade de estender à própria cidade as discussões e experimentações sobre o tema até então realizadas no âmbito acadêmico, e decidimos criar uma oportunidade de encontro entre artistas e especialistas das diversas áreas cujo enfoque de atuação profissional estivesse relacionado com o tema da relação entre corpo e cidade, para possibilitar a confrontação pública de suas proposições artísticas e teóricas.

Baseadas em tais pressupostos e preocupações, organizamos o evento Corpocidade: debates em estética urbana 1 (2008) como uma dessas zonas de transitividade propostas anteriormente, criando situações em que pudéssemos experimentar um padrão colaborativo não conciliatório mas criativo de alternativas, de modo que a articulação entre Arte e Urbanismo e outros campos correlatos como Filosofia, Psicologia e História nos permitisse conduzir suas questões específicas por caminhos de construção argumentativa abertos por discussões compartilhadas, promovendo a expansão de um campo no outro. 
A ideia de organizar esse encontro foi resultante do compartilhamento das ideias e posturas formuladas por um grupo de professores (alguns dos quais integraram o Comitê Científico), a partir de suas experiências de sala de aula sobre questões acerca de estética urbana. Buscamos, então, abranger aspectos da multiplicidade desse tema, que vai da estética do espaço urbano (cidade como obra de arte) à estética no espaço urbano (obra de arte na cidade), passando por considerações estéticas sobre intervenções urbanas, arte pública, performances, projetos urbanos etc.

A partir do nosso desafeto às ações isoladas e pontuais como os demais "eventos" realizados sobre o tema, percebemos a necessidade de pensar este encontro não mais como um fim em si mesmo, mas como uma das possíveis configurações de um projeto mais abrangente dedicado ao enfrentamento do problema da degradação da experiência pública das cidades contemporâneas por meio de produção crítica continuada e de atuações prospositivas. A própria experiência colaborativa de formatação e planejamento do encontro mostrou-se de tal modo enriquecedora dos nossos ideais de interlocução que decidimos expandir o raio de ação e ressonância do encontro e criar outros campos alternativos de participacão pública na nossa proposta, abrindo frestas de interferência no processo de maturação desse debate, por meio de um programa de ações complementares.

O encontro, então, inicialmente idealizado como um evento acadêmico-artístico com duração limitada a quatro dias (27 a 31/outubro/2008), logo adquiriu dimensões mais abrangentes e passou a ser gerido como uma "plataforma de ação": um conjunto de atividades públicas e ações diretivas destinadas a produzir e divulgar ideias, projetos e experiências de articulacão entre corpo e cidade, desenvolvidos em diferentes áreas do conhecimento e contextos culturais.

A primeira iniciativa da organização foi criar um site bilingue www.corpocidade.dan.ufba.br que atuasse, por um lado, como arquivo dinâmico de materiais diversos acerca do projeto e, por outro, como campo de divulgação/circulação de idéias, por meio da publicação de textos, projetos artísticos e urbanísticos. Assim surgiu a revista eletrônica [dobra], com periodicidade mensal e cuja editoria entregamos para estudantes bolsistas de mestrado em Arquitetura e Urbanismo e Dança, que haviam cursado, em 2007, a disciplina Estética Urbana, que as autoras lecionaram juntas no Programa de Pós-Graduação em Artes Visuais da UFBA, e cujo enfoque temático e dinâmica laboratorial já se definiam como opção metodológica de prática tanto crítica quanto interventiva que se intencionava estender para o contexto do encontro Corpocidade: debates em estética urbana 1 (2008).

Desde a criação do site, em fevereiro de 2008 até a realização do encontro, em outubro de 2008, na Escola de Dança da UFBA - Salvador/Bahia, foram publicadas cinco edições da revista [dobra], como ação preparatória do próprio evento. A primeira edição foi introdutória da proposta do evento e apresentou suas quatro Sessões Temáticas, a composição do comitê Científico-Artístico, a dinâmica dos trabalhos e as regras de participação. As outras quatro edições 
tematizavam, separadamente, cada uma das Sessões Temáticas, incluindo entrevistas, artigos, reportagens e imagens encomendadas a colaboradores convidados e ao próprio comitê Científico-Artístico do evento.

Para compor a programação dos debates, a organização do encontro lançou uma chamada de propostas ou respostas que poderiam ser teóricas ou artísticas a uma questão previamente colocada: a crítica prospectiva ao processo de espetacularização urbana. Tínhamos também, como uma pista a ser seguida, a questão da experiência ou da prática dos espaços públicos no cotidiano e, em particular, da própria experiência corporal destes. Ao buscar um escape dessa hegemonia das imagens consensuais, era evidente que a questão do corpo precisaria ser investigada, em particular as relações entre corpo e urbanismo, entre corpo urbano e corpo político, entre corpo da arte e corpo da cidade. E tínhamos como premissa básica o entendimento de que o estudo das relações entre corpo - corpo ordinário, vivido, cotidiano, ou seja, o corpo enquanto possibilidade de micro resistência à espetacularização, o oposto do corpo mercadoria, imagem ou simulacro, produto da própria espetacularização - e cidade, poderia nos mostrar alguns desvios a este processo sofrido pelas cidades contemporâneas.

O debate em estética urbana entre os campos da arte e do urbanismo proposto pelo encontro "corpocidade", buscou, ainda, articular políticas culturais a territórios urbanos. Pretendeu-se estimular uma discussão acerca dos modos como se processam as noções de corpo, arte, ambiência e cidade nas práticas e discursos produzidos em diferentes campos do conhecimento e, em particular, nas artes visuais, dança, arquitetura e urbanismo. Pretendeu-se discutir as diferentes articulações possíveis entre corpo e cidade como estratégia de redesenho das suas condições participativas no processo de formulação da vida pública em que estão co-implicadas. Pretendeu-se instaurar uma arena de debates para a confrontação de ideias e experimentação coletiva de hipóteses em formatos teóricos e artísticos. Criou-se, para isso, um contexto que atuasse como fórum de discussão das proposições inscritas - experimentações teóricas ou artísticas - para situá-las em termos teóricos e contextualizá-las histórica e politicamente, no confronto entre elas.

$\mathrm{O}$ encontro experimentou o formato de um encontro teórico-artístico para discutir as relaçõe entre "corpo" e "cidade" a partir da confrontação de ideias que se apresentaram como hipóteses (experimentações) teóricas ou artísticas (intervenções urbanas) de resposta às questões propostas pelas quatro sessões temáticas do encontro. Formuladas por um grupo de oito professores com atuação acadêmica em Programas de Pós- Graduação das áreas de Arquitetura e Urbanismo, Artes Visuais, Dança, História, Filosofia e Psicologia, cada ST expressou, em suas ementas, diferentes dimensões do tema e sugeriu modos de acesso e de interlocução específicos a seu contexto teórico. Para conduzir a seleção dos trabalhos, coordenar as apresentações das experimentações e participar dos debates, cada ST foi coordenada por um Comitê que decidimos caracterizar como Científico-Artístico composto de dois professores e um artista convidado, de modo a instaurar uma interlocução acadêmico-artística em todo o processo de construção do perfil do encontro. 
Intelectuais, críticos, professores, estudantes, arquitetos, urbanistas, artistas plásticos, coreógrafos, performers e demais artistas ou teóricos interessados no debate proposto pelo encontro foram convidados a participar. Recebemos centenas de propostas de comunicação e de intervenção de vários estados do país, assim como de outros países, dentre as quais, foram selecionadas 12 intervenções urbanas que foram realizadas em Salvador e 36 comunicações teóricas que foram apresentadas durante a programação de cada uma das quatro Sessões Temáticas, que ocuparam, cada uma, um dia do encontro, em debates com a presença de todos os participantes, dos membros do comitê e demais convidados. O limite de comunicações visou justamente evitar a sobreposição de apresentações na programação, para garantir a instauração de um verdadeiro debate em que cada sessão temática fosse articulada ao debate mobilizado pelas demais e todos os participantes pudessem participar de todas as discussões de modo a beneficiaremse mutuamente com perspectivas diferenciadas mas complementares.

A primeira ST do encontro, coordenada por Margareth da Silva Pereira (PROURB/UFRJ) e a colaboração de Regina Helena da Silva (PPGHIS/UFMG) e da artista Daniela Brasil (Bauhaus/Weimar) tratou da questão das CIDADES IMATERIAIS, foi colocada questão a hipertrofia da dimensão material e visual na compreensão do conceito de "cidade", que continua a ignorar indivíduos ou grupos e a diversidade de suas histórias, memórias e experiências de vida coletiva. Pretendeu-se discutir como a banalização de elogios ou condenações implícitas em expressões que vêm sendo invocadas hoje - como "cidades genéricas", "cidades partidas", "cidades em trânsito", "cidades sem limites" - não são inocentes e negligenciam que as cidades são construções plurais, ao mesmo tempo materiais, imateriais, mas, sobretudo, "encarnadas", feitas, portanto, de subjetividades, percepções, expectativas, alianças, conflitos que elaboram a própria tessitura social, política e cultural em seu modo mais banal, cotidiano e dinâmico de ação. Foi enfatizada a discussão de situações de nomadismos, exílios, hibridismos ou mestiçagens capazes de chamar a atenção para a diversidade de "cidades" que sempre estiveram presentes na experiência citadina, autorizando expressões culturais - arquitetônicas, urbanísticas, artísticas - que deslocam a pregnância de um conceito material, construído, visível e fechado de cidade que já demonstrou seus limites e as exclusões que acarreta.

Na segunda ST do encontro, coordenada por Glória Ferreira (PPGAV/ UFRJ) e a colaboração de Guilherme Bueno (EAVPL/RJ) e do artista Ronald Duarte (RJ), o tema tratado foi a "cidade como campo ampliado da arte", a cidade foi discutida como situação da ampliação do campo artístico. Vimos que o investimento de diferentes tipos de ações de artistas nas últimas décadas estabeleceu uma nova cartografia simbólica da arte na qual se tecem nexos com as situações históricas, políticas e sociais, bem como com o fluxo de significações de sua presença no mundo. A relação com a cidade indica, assim, a busca de uma economia de inserção da arte nas sociedades e no mundo, redefinindo a função, o papel e mesmo o que seria próprio à arte nas atuais circunstâncias. 
A terceira ST do encontro, coordenada por Fabiana Dultra Britto (PPGDAN/UFBA) e a colaboração de Paola Berenstein Jacques (PPGAU/UFBA) e do coreógrafo Alejandro Ahmed (Grupo Cena 11/SC) tratou diretamente da ideia de "corpografias urbanas", ou seja, a idéia de se explorar o campo de possibilidades das relações entre corpo e cidade pensando-as como um processo de formulação de um ambiente e o ambiente como conjunto de condições para a continuidade desse processo. Corpo e cidade se relacionam, mesmo que involuntariamente, por meio de toda e qualquer experiência urbana. A cidade é lida pelo corpo como conjunto de condições interativas e o corpo expressa a síntese dessa interação descrevendo em sua corporalidade, o que passamos a chamar de "corpografia urbana". Nesta ST investigamos as cartografias realizadas pelo e no corpo como registros corporais das experiências urbanas, e bucasmos compreender espaços urbanos através de diferentes configurações corporais.

A quarta e última ST, coordenada por Robert Pechman (IPPUR/UFRJ), juntamente com Luis Antônio Baptista (PPGPS/UFF) e a videoartista Eliana Kuster (ES), propôs questionamos sobre os "modos de subjetivação na cidade": Como entender os modos de subjetivação do indivíduo contemporâneo na cidade? Uma cidade, já sabemos, é mais do que um simples lugar, é mais que um cenário, transcende o palco. Segundo o coordenador da ST:

A cidade é a possibilidade do individuo ser: quanto mais ela é introjetada no plano familiar, íntimo, pessoal, quanto mais ela parece estruturar o indivíduo no plano familiar, tanto mais ela compõe, de fato, o ser urbano. Ora, quem pensa cidade não escapa ao "socius" e se vê diante da urbanidade: o verdadeiro "ethos" de uma cidade. Trata-se, portanto de refletir/experimentar as derivas urbanas do corpo contemporâneo em torno das novas formas de urbanidade, inclusive aquelas capazes de negar a própria cidade. Teríamos o quê, então? Um corpo sem urbanidade, logo, sem cidade, cujo modo de subjetivação escapa completamente ao chão que o pariu? Qual seria então a equação? Tal corpo, qual cidade? Ou o seu inverso?

Haveria muito que comentar acerca dos trabalhos teóricos e artísticos apresentados, bem como da própria dinâmica de debates que se instaurou ao longo dos quatro dias do encontro, contudo, pretende-se fazê-lo em outra oportunidade. O que importa salientar aqui é que todas as propostas de intervenções urbanas enviadas pelos artistas e selecionadas (pelo comitê artístico do encontro), direta ou indiretamente, exploravam, explicitavam ou criavam essas tensões no/do espaço público contemporâneo no próprio espaço público local a cidade de Salvador. E a articulação promovida entre as intervenções artísticas realizadas durante o encontro e os debates diários mobilizados pelas Sessões Temáticas, permitiu uma análise crítica das situações problematizadas pelos artistas e pelos propositores teóricos a partir da própria experiência vivida pelos participantes, organizadores e habitantes da cidade nas instâncias de montagem e execução das propostas de intervenção. $\mathrm{O}$ acompanhamento participativo desse processo explicitou justamente o aspecto aqui tratado como foco de preocupação: a tendência crescente de eliminação ou pacificação de conflitos, em curso nos projetos de espaços públicos contemporâneos, e o papel da arte contra-hegemônica enquanto possibilidade de micro-resistência a este processo. 


\section{Notas}

${ }^{1}$ É possível se falar em processos urbanos distintos, como culturalização, patrimonialização, museificação, musealisação, estetização, turistificação, gentrificação, mas estes fazem parte de um mesmo processo contemporâneo e mais vasto chamado de espetacularização urbana. Este processo, por sua vez, está diretamente relacionado com as novas estratégias de marketing, ou mesmo o que podemos chamar hoje de branding urbano (construção de marcas) dos projetos ditos de revitalização urbana que buscam construir uma nova imagem para as cidades contemporâneas de modo a lhes garantir um lugar na nova geopolítica das redes globalizadas de cidades turísticas e culturais. Na lógica contemporânea de consumo cultural massificado, a cultura é concebida como uma simples imagem de marca ou grife de entretenimento, a ser consumida rapidamente. Com relação às cidades, ocorre algo semelhante: a competição, principalmente por turistas e investimentos estrangeiros, é acirrada e os políticos, com apoio dos empreendedores do setor privado, se empenham para melhor construir e vender a imagem de marca, ou o logotipo, de suas cidades cenográficas, cada dia mais padronizadas e uniformizadas. Uma longa discussão sobre o tema pode ser encontrada em "Espetacularização urbana contemporânea" (JACQUES, 2004).

${ }^{2}$ Uma discussão dedicada ao modo como corpo e ambiente se relacionam encontra-se publicada no número Especial da revista Cadernos do PPGAU/UFBA, Paisagens do Corpo, Salvador, 2008. Disponível para download em: http://www.laboratoriourbano.ufba.br/pagina.php?idPagina=5

${ }^{3}$ Paul Thagard (2000), define coerência como a máxima satisfação de múltiplas restrições, Esta idéia permite pensar a instauração de coerências como uma resultante da reorganização dos sistemas que, envolvidos em processo co-evolutivo, precisam satisfazer as múltiplas restricões impostas pelas configurações dos sistemas e sub-sistemas (ambientes) com que interagem. Ver BRITTO, Fabiana Dultra: Temporalidade em Dança: parâmetros para uma história contemporânea - Tese de Doutorado defendida em 2002 e publicada pelo FID Editorial, Belo Horizonte, 2008.

${ }^{4} \mathrm{~A} 1^{\mathrm{a}}$ versão do texto Corpografias Urbanas - com ênfase na idéia do corpo enquanto resistência - foi publicado no Cadernos do PPG-AU especial "Resistências em espaços opacos", Salvador, 2007. Um desenvolvimento dessas idéias- com ênfase na idéia da corpo enquanto fenótipo extendido - em co-autoria com Fabiana Britto (Programa de Pós-Graduação em Dança da UFBA) foi publicado no Cadernos do PPG-AU especial "Paisagens do corpo", Salvador, 2008. Essas são publicações dos resultados de pesquisa do projeto CAPES-COFECUB "Territórios Urbanos e Políticas Culturais". Trata-se do terceiro e último número especial resultante das atividades deste acordo, o primeiro Territórios Urbanos e Políticas Culturais foi publicado em 2004 e o segundo, Resistências em Espaços Opacos, em 2007. Se no primeiro número os textos tratam principalmente da crítica à culturalização, estetização e espetacularização das cidades, no segundo os artigos já buscam algumas alternativas a estes processos contemporâneos, principalmente em ações culturais de resistência urbana. Foi neste contexto de busca de ações moleculares de resistência ao processo molar de espetacularização - da cidade, da arte e do próprio corpo - na contemporaneidade, que surgiu a urgência de uma reflexão conjunta - entre os campos da Arquitetura e Urbanismo e da Dança - sobre as atuais relações entre cidade e corpo, entre o corpo urbano e o corpo do cidadão. 


\section{REFERÊNCIAS}

BRITTO, F. D. Temporalidade em Dança: parâmetros para uma história contemporânea. 1. ed. Belo Horizonte: FID, 2008. Publicação da tese de Doutorado defendida em 2002.

. (Org.). Cartografia da Dança. São Paulo: Itaú Cultural, 2001. 144 p.

CORPOCIDADE: DEBATES EM ESTÉTICA URBANA, 1., 2008. Salvador: UFBA, 2008. Disponível em: <http://www.corpocidade.dan.ufba.br/>. Acesso em: 20 abr. 2009.

DEBORD, G. A sociedade do espetáculo. Rio de Janeiro: Contraponto, 1997.

[dobra]. Salvador: UFBA, 2008-. Mensal. Disponível em: <http://www. corpocidade.dan.ufba.br/dobra/01_01_editorial.htm>. Acesso em: 25 maio 2009.

JACQUES, P. B. Les favelas de Rio. Paris: l'Harmattan, 2001a.

. Estética da Ginga. Rio de Janeiro: Casa da Palavra, 2001b.

Esthétique des favelas. Paris: 1'Harmattan, 2003a.

. (Org.) Apologia da Deriva. Rio de Janeiro: Casa da Palavra, $2003 b$.

. Espetacularização urbana contemporânea. In: FERNANDES, A.; JACQUES, P. B. (Org.) Territórios urbanos e políticas culturais. Cadernos PPG - AU FAUFBA, ano II, no especial, p. 23-30, 2004.

. Corps et Décors urbains. Paris: 1'Harmattan, 2006.

. Corpografias urbanas: o corpo enquanto resistência. Cadernos $P P G$

- AU - FAUFBA: Resistências em espaços opacos. Salvador, Ano 5, número especial, p. 93-104, 2007.

JACQUES, P. B. (Org.) ; BRITTO, F. D. (Org.) Paisagens do Corpo. Salvador: PPG-AU FAUFBA, 2008. ano VI, número especial da revista Cadernos do PPGAU/UFBA. Disponível em: <http://www.laboratoriourbano.ufba.br/ download.php?idArquivo=16>. Acesso em: 03 maio 2009.

JEUDY, H. P.; JACQUES, P. B. Corpos e cenários urbanos. Salvador: EDUFBA, 2006.

JEUDY, H. P. Les usages sociaux de l'art. Paris: Circé, 1999. 
MOUFFE, C. Politicas artisticas y democracia agonística. Barcelona: Bellaterra (Cerdanyola del Vallès), 2007a.

. Artistic Activism and Agonistic Spaces. Art \& Research: a journal of ideas, contexts and methods, London, v. 1, n. 2. , 2007b. Disponível em: <http:// www.artandresearch.org.uk/v1n2/mouffe.html>. Acesso em: 14 maio 2009.

RANCIÉRE, J. Sobre politicas estéticas. Barcelona: Bellaterra (Cerdanyola del Vallès), 2005.

. O desentendimento: política e filosofia. São Paulo: Editora 34, 1996.

THAGARD, P. Coherente in thought and action. Massachussets: MIT, 2000.

VARELLA, D.; BERTAZZO, I.; JACQUES, P. B. Maré: vida na favela. Rio de Janeiro: Casa da Palavra, 2002.

Recebido em: junho de 2009 Aceito em: agosto de 2009 